\title{
Fidelity to spawning grounds by a catadromous fish, Centropomus undecimalis
}

\author{
Aaron Adams ${ }^{1, *}$, R. Kirby Wolfe ${ }^{1,4}$, Nicholas Barkowski ${ }^{2}$, Dana Overcash ${ }^{3}$ \\ ${ }^{1}$ Mote Marine Laboratory, Charlotte Harbor Field Station, PO Box 2197, Pineland, Florida 33945, USA \\ ${ }^{2}$ Carroll University, 100 N. East Avenue, Waukesha, Wisconsin 53186, USA \\ ${ }^{3}$ Villanova University, 800 Lancaster Avenue, Villanova, Pennsylvania 19085, USA
}

${ }^{4}$ Present address: Habitat Program, Marine Fisheries Section, Coastal Resources Division, Georgia Department of Natural Resources, One Conservation Way, Suite 300, Brunswick, Georgia 31520-8687, USA

\begin{abstract}
There is increasing recognition that many traditionally managed marine fish stocks have metapopulation structure resulting from fidelity to spawning grounds. Such fidelity may result in population segregation, even if this segregation is not evident through genetic testing. Homing to spawning grounds is well documented for anadromous salmonids, but less so for broadcast-spawning marine fishes. This study used tag-recapture (external dart tags and internal PIT tags) and tracking (sonic transmitters and stationary receivers) to examine the potential site fidelity of mature common snook Centropomus undecimalis to coastal spawning grounds (barrier islands) of the Gulf of Mexico coast of Florida, USA, in 2 consecutive spawning seasons. Of the 63 fish (3.5\% of tagged fish) recaptured within and between years, all occurred at the same island where the fish was tagged. Of the sonic-tagged snook with sufficient detections to determine movement patterns, $88.3 \%$ were detected only at the island where they were tagged. The low average distance between tag and recapture locations, and the high individual residence times at few receiver locations, suggest that fidelity may occur at an even smaller scale than the barrier island. Since spawning ground fidelity may mean that different spawning groups are subject to different conditions, and the ability of a stock to respond to anthropogenic or natural stressors may be influenced by such segregation, additional research is needed to determine the implications of spawning ground fidelity by common snook.
\end{abstract}

KEY WORDS: Acoustic telemetry $\cdot$ Centropomus undecimalis $\cdot$ Fish spawning $\cdot$ Homing $\cdot$ Site fidelity Tag-recapture

Resale or republication not permitted without written consent of the publisher

\section{INTRODUCTION}

There is an increasing recognition that many traditionally managed marine fish stocks have metapopulation structure (Hanski \& Gilpin 1997), which may influence population response to stressors. The metapopulation structure may result from numerous subpopulations or from segregation of spawning groups with various levels of genetic exchange (Smedbol \& Stephenson 2001). For many marine fishes, the degree of subpopulation structure or spawning group segregation has not been examined.

Segregation of spawning groups occurs when individuals show fidelity to distinct spawning locations. Spawning site fidelity may be derived in one of 3 ways: (1) formed at first maturity (spawning-group fidelity)
(Robichaud \& Rose 2001); (2) individuals return to their natal location to spawn (philopatry) (Robichaud \& Rose 2001); or (3) spawning location may be learned as part of a social learning process (learned) (Colin 1996). Regardless of the mechanism, fidelity to spawning grounds may result in population segregation, even if this segregation is not evident through genetic testing. Spawning site fidelity may mean that different spawning groups are subject to different conditions, and the ability of a stock to respond to anthropogenic or natural stressors may be influenced by such segregation.

Homing to spawning grounds is well documented for anadromous salmonids (e.g. Groot \& Margolis 1991), and the fisheries for these species are often managed accordingly. For example, the impact of recognized stressors (natural or anthropogenic) on specific spawn- 
ing groups can be addressed through a variety of measures, including spawning area closures. Research documenting the homing of coral reef fishes (e.g. Nassau grouper, Aguilar-Perera \& Aguilar-Davila 1996) to spawning locations has been used to institute spatial or temporal closures to protect populations from overfishing (e.g. Beets \& Friedlander 1999). Even in situations where changes in management are unable to address metapopulation structure due to spawning segregation, understanding that the segregation exists helps to explain success or failure of population models. For example, the slower than expected recovery of Atlantic cod may be in part due to a greater degree of spawning segregation than had been recognized, because site fidelity impedes recolonization of spawning grounds (Robichaud \& Rose 2001). Moreover, recognition of spawning segregation can be used in proactive management by incorporating this knowledge into spatial models of actual and anticipated stressors such as harmful algal blooms or anthropogenic habitat degradation.

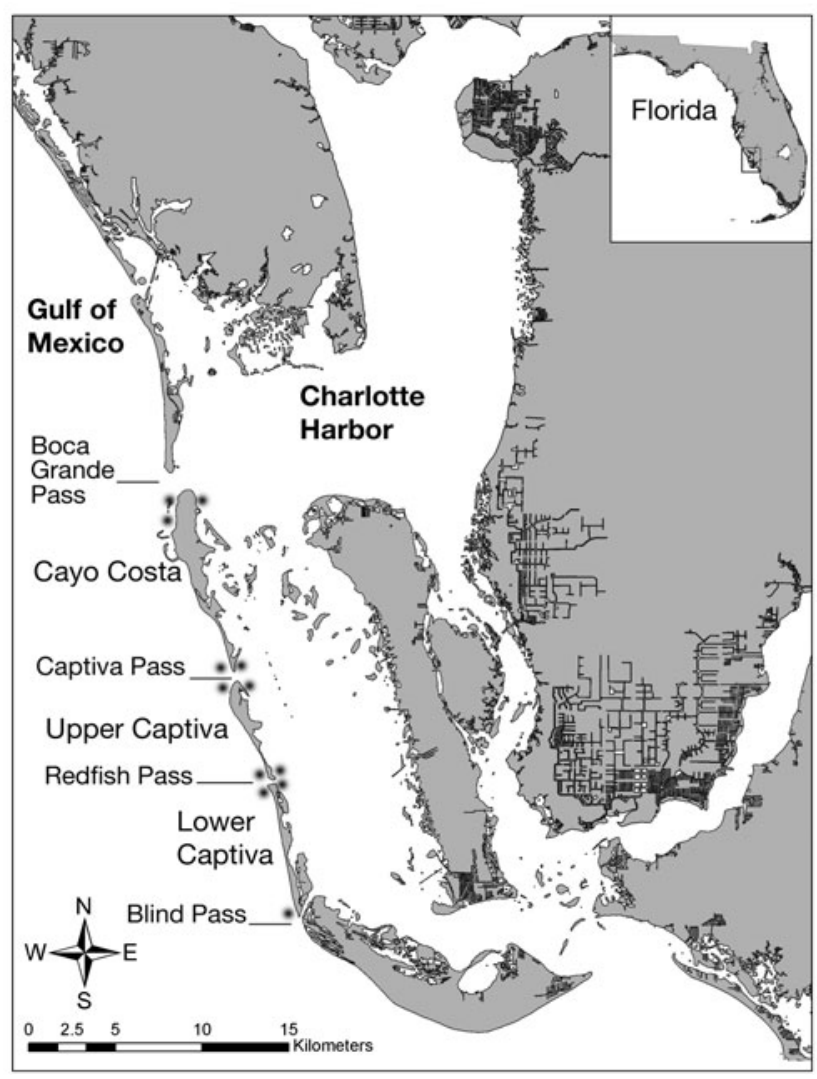

Fig. 1. Study locations in southwest Florida, USA. Tag and recapture by seine occurred along barrier island beaches from the northern end of Cayo Costa (at Boca Grande Pass) to the southern end of Lower Captiva (at Blind Pass). Potential area of recapture by recreational anglers using hook and line included the entire area shown. Potential area of recapture by FWRI FIM sampling was within the estuary. Fuzzy black circles: acoustic receiver locations
Common snook Centropomus undecimalis is an estuarine-dependent catadromous fish present throughout the Caribbean Sea, and as far north as central Florida, USA (Taylor et al. 1998). In Florida, common snook is an economically important recreational species that receives intensive fishing pressure and is under strict management regulation (Taylor et al. 1998). The juvenile stage is dependent upon oligo- and mesohaline wetland habitats, whereas adults forage throughout the estuary but are dependent upon saline coastal waters for spawning (Taylor et al. 1998). In portions of their range in Florida, adult common snook during spawning season are exposed to blooms of the toxic dinoflagellate Karenia brevis that has salinity and temperature requirements similar to spawning snook (Vargo 2009). These blooms are patchy both spatially and temporally, as are the effects on snook. Although the general patterns of snook spawning are known (season, spawning grounds; Taylor et al. 1998), the degree to which snook show fidelity to spawning grounds remains unknown. The level of spawning ground fidelity by snook is needed to predict localized and population-level effects of natural disturbances such as $K$. brevis. The present study used tag-recapture techniques to determine whether snook exhibit fidelity to spawning grounds within and between years along the Gulf coast of Florida.

\section{MATERIALS AND METHODS}

Study area. Charlotte Harbor is a $700 \mathrm{~km}^{2}$ coastal plain estuarine system in southwest Florida (Hammett 1990) (Fig. 1). The Peace, Myakka, and Caloosahatchee Rivers, as well as many smaller creeks throughout the drainage, transport large amounts of fresh water into the harbor. The climate is subtropical; mean seasonal water temperatures range from 12 to $36^{\circ} \mathrm{C}$, and freezes are infrequent (Poulakis et al. 2003). The estuary is separated from the Gulf of Mexico by a string of barrier islands, with tidal exchange through 4 inlets that separate the barrier islands - Boca Grande Pass, Captiva Pass, Redfish Pass, and San Carlos Pass. The Gulf-side shorelines of the islands are comprised entirely of sandy beaches. The passes are a mixture of natural sand and anthropogenically hardened shorelines. Common snook spawn in proximity to the passes and at a few locations along the barrier island beaches during summer (typically May through September) (Taylor et al. 1998, A. J. Adams pers. obs.).

Capture protocol. From May through September 2007 and 2008, snook were captured along Gulf beaches of 3 barrier islands - Cayo Costa $(12.4 \mathrm{~km}$ long), Upper Captiva $(6.8 \mathrm{~km})$, and Lower Captiva $(8.9 \mathrm{~km})$ - between Boca Grande Pass and Blind Pass 
(Fig. 1). The number of sample days per month was similar among islands: Cayo Costa (2007/2008, respectively: May 5/3, June 3/9, July 9/6, August 6/8, September 3/11); Upper Captiva (May 5/5, June 6/7, July 6/13, August 4/8, September 2/4); Lower Captiva (May 1/3, June 8/4, July 6/8, August 3/11, September $4 / 4)$. The number of samples per day ranged from 1 to 7 and depended on the number of snook spotted and captured. Sampling occurred between 07:00 h (onset of suitable sunlight for sighting fish) and 12:00 h (increase in volume of human activity on beaches, water temperatures at stressful levels for snook). Sampling occurred as conditions allowed-onshore winds and/or high surf prevented sampling, as did proximity of hurricanes - and did not focus on a particular lunar phase. On each sample day, the entire length of beach that could be sampled on each island (i.e. free of trees and other debris) was searched if time allowed. A shallow-draft net boat was used to set seine nets around schools of common snook that were spotted along the beach. The procedure was to steer the boat along the beach and, when snook were spotted, one end of the net was deployed off the back of the boat and the boat used to set the net around the school. The entire length of beach of each island was searched for snook on each day the island was sampled. During summer, snook typically hold within $2 \mathrm{~m}$ of shore, so this method is very effective. Two center-bag seine nets (91.44 $\times$ $2.44 \mathrm{~m}$ with $19.05 \mathrm{~mm}$ mesh and $182.88 \times 2.44 \mathrm{~m}$ with $15.00 \mathrm{~mm}$ mesh) were used during the present study. The nets were hauled onto shore and the fish captured in the center bag. Once captured, the snook were placed in mesh holding pens until tagging.

Tag-recapture. Tagging: Snook were tagged internally with 23 mm HDX Passive Integrated Transponder (PIT) tags (TIRFID 2000, Texas Instruments) and external T-bar anchor or dart tags (Floy Tag \& Manufacturing). Prior to tagging, snook were removed from the holding pens, and placed in a cooler with a seawater and Alka-Seltzer mix (1 to 1.5 tabs per 41 seawater) to anesthetize the fish. Once anesthetized, a PIT tag was inserted into the abdominal cavity through a $3 \mathrm{~mm}$ incision (sensu Adams et al. 2006), and a T-bar anchor or dart tag inserted below the dorsal fin. (We converted from T-bar anchor to dart tags during the course of the study [on 3 July 2008] due to tag loss of the T-bar anchor tags.) Each external tag was imprinted with an identification number and phone number to report a recapture. Each PIT tag has a unique 10-digit identification number. Standard length (SL), external tag identification number, PIT tag number, and latitude and longitude were recorded for each fish. After tagging, fish were placed in a recovery pen for approximately $5 \mathrm{~min}$ and released at the site of capture. No mortality of snook after tagging and release was observed, and since tagging experiments with juvenile snook reported low or no mortality (Adams et al. 2006), post-tagging mortality in the present study was assumed to be minor.

Recapture: Recapture occurred by seine during tagging efforts, by recreational anglers using hook and line, or by the state of Florida Fish and Wildlife Research Institute's (FWRI) Fisheries Independent Monitoring (FIM) program using seines. The present study's seine sampling effort occurred entirely along the Gulf of Mexico beaches of the barrier islands. The potential recapture area for recreational angler recaptures included all estuarine and coastal habitats in the region. The FWRI sampling effort was along shorelines and seagrass beds of the Charlotte Harbor estuary, Pine Island Sound, and Caloosahatchee River (Fig. 1), and occurred 12 mo per year.

During seine sampling and prior to tagging, all snook were scanned with an Allflex ISO compatible RFID portable reader for PIT tags (model no. RS601, Allflex) and inspected for external tags. In addition, on numerous sampling days, snook were not tagged - all captured fish were checked for tags and released. For recaptures, tag identification numbers, latitude and longitude, and SL were recorded and the fish were released. Three Allflex RFID portable readers were also distributed to local recreational fishing charter captains who frequently targeted snook. If PIT tags were detected, the guides recorded the location of the recapture and the PIT tag identification number. Recreational anglers who caught snook with external tags were asked to report the catch to the phone number listed on the tag, and to provide the tag identification number, fish length, and location of capture. If latitude and longitude coordinates were not available, specific location information was obtained so that the recapture location could be closely approximated.

Analysis. The locations of tag and recapture were plotted to visually determine whether snook were recaptured close to the tagging site, and latitude and longitude coordinates used to determine distance locations. Since $100 \%$ of recaptures within each spawning season occurred on the same barrier island where the fish was tagged, distances between tagging and recapture locations were pooled by island and examined with a 1-way ANOVA by island. Year was not used as a factor because there were no recaptures on Lower Captiva in one year. Days at large (number of days between tagging date and recapture date) were calculated for each snook recaptured in the same season it was tagged, and examined within each season using a 2-way ANOVA (with Island and Year as factors).

Acoustic telemetry. Tagging: Thirty snook (approximately 10 per barrier island) $>450 \mathrm{~mm}$ SL were randomly selected over the course of each summer 
for tagging. Acoustic transmitters (V13-1H-A69-1303, Vemco, $13 \times 36 \mathrm{~mm}$, transmit interval minimum $=40$, maximum $=120 \mathrm{~s}$ ) were surgically implanted in the abdominal cavity of selected snook. Snook were placed in a cooler with a seawater and Alka-Seltzer mix (1 to 1.5 tabs per 41 seawater) to anaesthetize the fish prior to surgery, and remained anaesthetized through stitching. After the incision was made, the sex of the fish was determined by noting ovaries or testes. The transmitter was then inserted and the incision closed with 3 stitches. The snook was then placed in a floating pen for recovery prior to release at the site of capture. Snook were released once they were swimming energetically (5 to $15 \mathrm{~min}$ ). SL and latitude and longitude were recorded for each fish. One incident of postrelease mortality was observed: a large barracuda Sphyraena barracuda preyed upon a recently released snook with an acoustic transmitter. Although no other incidences of predation were observed, post-release mortality was not measured. Large barracuda are present seasonally, but were rare in the study area. Other potential predators were bottlenose dolphin Tursiops truncatus, bull shark Carcharhinus leucas, and blacktip shark C. limbatus.

Monitoring: Twelve acoustic receivers (VR2W, Vemco) were placed adjacent to 3 passes between barrier islands and along the beach at a defunct pass (Blind Pass) filled in by sedimentation (Fig. 1), effectively bracketing the study area. Water depth at receiver locations ranged from 2 to $5 \mathrm{~m}$. Each receiver was attached with cable ties to a braided nylon rope that was attached to an anchor and subsurface float so that the receiver was suspended $1 \mathrm{~m}$ above the bottom. The receiver locations allowed monitoring of snook passage through the passes and/or their holding in areas in or near the passes, with the array designed to answer the specific question: do snook show fidelity to an area during spawning season or do they travel among islands? Receivers were downloaded and maintained every other month. Data were examined to determine the spatio-temporal patterns of snook occurrence at the passes. The detection range of each receiver was tested using a sonic transmitter towed by kayak from the receiver to shore, with transmitter depth maintained near the bottom. Range testing occurred near low tide, when wave noise and interference by sandbars would make detection most difficult. In all cases, detection range extended to shore as well as offshore $>100 \mathrm{~m}$. Since the expectation was that snook primarily move along shore close to the shoreline, most, if not all, snook were expected to pass within range of the receivers.

\section{RESULTS}

\section{Tag-recapture}

A total of 756 snook were tagged in 2007, and 1051 in 2008 (Table 1). Although sampling effort was similar on all islands, more snook were tagged on Cayo Costa (772) than Lower Captiva (606) or Upper Captiva (429). Tagged snook ranged in size from 316 to $851 \mathrm{~mm}$ (mean $=421.98 \mathrm{~mm})$, and although the size range was similar on all islands, there were proportionally more large snook captured on Lower Captiva (Fig. 2).

Sixty-three tagged snook were recaptured along barrier island beaches during the 2007 and 2008 spawning seasons, for an overall $3.5 \%$ recapture rate. Thirty-nine tagged snook were recaptured in the same year as they were tagged, and 24 snook tagged in 2007 were recaptured in 2008. Recapture rates were higher in 2007 than 2008, and in 2008 there were more interannual recaptures than within-year recaptures. Of the total recaptured snook, 50 were recaptured during seine sampling, and 13 were recaptured by recreational anglers or charter captains. Lengths of recaptured snook were within the range of the overall tagged population (population mean $\pm \mathrm{SE}=421.98 \pm 1.33 \mathrm{~mm}_{\text {; }}$ recaptured snook mean $=426.6 \pm 6.23 \mathrm{~mm}$; ANOVA, $F=2.874, \mathrm{p}>$ $0.05, \mathrm{df}=1,1834$ ), thus the results are applicable to the entire sampled spawning population. With one exception, large snook (>600 mm) were missing from recaptures, but these large fish were also uncommon in seine

Table 1. Centropomus undecimalis. Number of common snook tagged and recaptured during the spawning season (May through September) by island and year. All snook were recaptured on the island where they were tagged (both within and between years). Within each year, recaptures are for fish only tagged within that year. Interannual recaptures indicate snook tagged in 2007 and recaptured in 2008

\begin{tabular}{|c|c|c|c|c|c|c|c|c|}
\hline \multirow[t]{3}{*}{ Island } & \multicolumn{3}{|c|}{2007} & \multicolumn{3}{|c|}{-2008} & \multirow{2}{*}{\multicolumn{2}{|c|}{$\begin{array}{l}\text { Interannual recaptures } \\
\text { Recaptured }\end{array}$}} \\
\hline & \multirow{2}{*}{$\begin{array}{c}\text { Tagged } \\
\mathrm{n}\end{array}$} & \multicolumn{2}{|c|}{ Recaptured } & \multirow{2}{*}{$\underset{\mathrm{n}}{\text { Tagged }}$} & \multicolumn{2}{|c|}{ Recaptured } & & \\
\hline & & $\mathrm{n}$ & $\%$ & & $\mathrm{n}$ & $\%$ & $\mathrm{n}$ & $\%$ \\
\hline Cayo Costa & 291 & 17 & 5.8 & 481 & 7 & 1.5 & 14 & 1.8 \\
\hline Upper Captiva & 163 & 7 & 4.3 & 266 & 7 & 2.6 & 6 & 1.4 \\
\hline Lower Captiva & 302 & 0 & 0.0 & 304 & 1 & 0.3 & 4 & 0.7 \\
\hline Total & 756 & 24 & 3.2 & 1051 & 15 & 1.4 & 24 & 1.3 \\
\hline
\end{tabular}



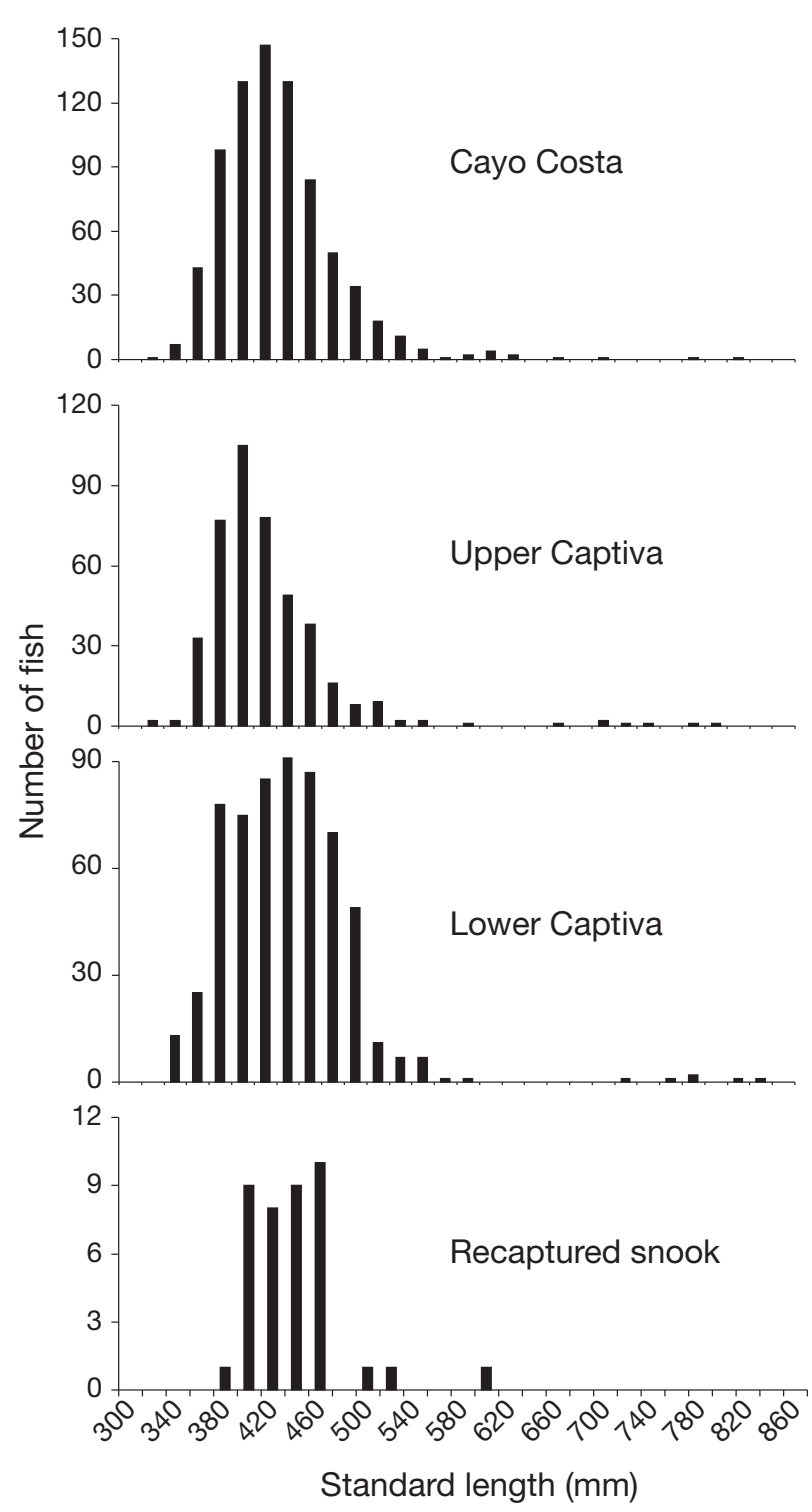

Fig. 2. Centropomus undecimalis. Length frequencies of tagged snook (by island) and recaptured snook (all islands combined). Data are combined for both 2007 and 2008

catches (Fig. 2). Distances between tagging and recapture locations were significantly less on Upper Captiva $($ mean $\pm \mathrm{SE}=1.98 \pm 0.46 \mathrm{~km})$ than Lower Captiva $(2.5 \pm$ $0.84 \mathrm{~km})$ and Cayo Costa $(2.25 \pm 0.52 \mathrm{~km})$, which were not significantly different (ANOVA, $F=9.191$, p $<0.01$, $\mathrm{df}=2,49$; Tukey's test, $\mathrm{p}<0.05)$. Upper Captiva $(6.76 \mathrm{~km})$ was also shorter in length than Lower Captiva $(8.85 \mathrm{~km})$ and Cayo Costa $(12.39 \mathrm{~km})$. There was no significant difference in days at large by Island or Year for snook tagged and recaptured in the same year (ANOVA, Island $F=0.055, \mathrm{p}>0.1, \mathrm{df}=1$; Year $F=0.08$, $\mathrm{p}>0.1, \mathrm{df}=1$; Island $\times$ Year $F=0.103, \mathrm{p}>0.1, \mathrm{df}=2$; error $\mathrm{df}=31$ ): the overall mean days at large was $48.03 \pm 7.48$.
Overall, patterns of snook spawning ground fidelity were similar on all 3 islands sampled in the present study. All except 2 snook recaptured during the spawning season were recaptured on the same island where they were tagged, both within and between spawning seasons. Two snook were recaptured in the estuary in September (one each in 2007 and 2008), at the end of spawning season (11 and 24 September, respectively). These fish were likely done spawning because they were recaptured in areas that did not meet spawning requirements (low salinity, shallow seagrass habitats within the estuary), so presumably they had migrated back to estuarine habitats. These 2 fish were not included in analyses.

\section{Acoustic telemetry}

Thirty snook were fitted with acoustic transmitters in the summer of both 2007 and 2008. For both years combined, $88.3 \%$ of snook that were detected were only detected on the island they were tagged. In 2007, 25 of 30 snook were detected at least once, and 19 had sufficient detections to warrant further examination (Table 2). (Some snook were detected only on a single day or up to 3 consecutive days at a single receiver, so provided insufficient data to examine seasonal movement patterns, and were excluded from further examination. All of these fish were observed on the same island where they were detected, so their exclusion makes this a conservative estimate of spawning ground fidelity.) Of these 19 snook, 10 were detected only on the island where they were tagged and only at one pass, 6 were detected only on the island where they were tagged but at passes at each end of the island, and 2 were detected on more than one island. In 2008, 24 of 30 snook were detected at least once, and 15 had sufficient detections to warrant further examination (see above explanation for exclusion of fish from analysis). Of these 15 snook, 8 were detected only on the island where they were tagged and only at one pass, 5 were detected only on the island where they were tagged but at passes at each end of the island, and 2 were detected on more than one island. Five snook tagged during summer 2007 were detected during summer 2008, and in all cases they were detected only at the receivers where they were detected in 2007, showing interannual site fidelity. Snook sex and size had no apparent influence on the pattern of movement.

The detections of all 4 snook that apparently traveled away from the island at which they were tagged occurred at Redfish Pass, and suggest only brief movements to a second island or detection of a transmitter from across the pass. Two snook (one detected only once, the other 10 times over 3 separate days) may 
Table 2. Centropomus undecimalis. Summary of acoustic receiver detections of adult snook fitted with acoustic transmitters during summer spawning seasons of 2007 and 2008. CC: Cayo Costa; UC: Upper Captiva; LC: Lower Captiva. CP: Captiva Pass; RF: Redfish Pass; BP: Blind Pass; BG: Boca Grande Pass. See Fig. 1 for locations of islands and passes. Months during the spawning season when snook were detected are within the tagging year unless noted; ${ }^{*}$ : fish tagged in 2007 that were detected in 2007 (Month(s) detected) and in at least one month in 2008. F: showed fidelity to one end of a barrier island; I: showed fidelity at the island scale; T: detected at more than one island

\begin{tabular}{|c|c|c|c|c|c|c|c|c|}
\hline $\begin{array}{l}\text { Year } \\
\text { tagged }\end{array}$ & $\begin{array}{l}\text { Month } \\
\text { tagged }\end{array}$ & $\begin{array}{l}\text { Transmitter } \\
\text { ID }\end{array}$ & Sex & $\begin{array}{c}\text { Standard } \\
\text { length }(\mathrm{mm})\end{array}$ & $\begin{array}{l}\text { Island of } \\
\text { tagging }\end{array}$ & $\begin{array}{c}\text { Pass where } \\
\text { detected }\end{array}$ & $\begin{array}{l}\text { Month(s) } \\
\text { detected }\end{array}$ & $\begin{array}{c}\text { Fidelity } \\
\text { classification }\end{array}$ \\
\hline \multirow[t]{19}{*}{2007} & \multirow[t]{3}{*}{ May } & 2813 & Female & 485 & $\mathrm{CC}$ & BG & May & F \\
\hline & & $2814^{*}$ & Male & 491 & $\mathrm{CC}$ & $\mathrm{CP}$ & Jun, Jul, Aug & $\mathrm{F}$ \\
\hline & & 2817 & Unknown & 446 & $\mathrm{CC}$ & $\mathrm{CP}$ & Jun, Jul, Aug, Sep & $\mathrm{F}$ \\
\hline & \multirow[t]{9}{*}{ June } & 2828 & Male & 493 & $\mathrm{UC}$ & $\mathrm{RF}$ & Jul & $\mathrm{F}$ \\
\hline & & 2830 & Unknown & 463 & UC & $\mathrm{CP}, \mathrm{RF}$ & Jun, Jul & $\mathrm{T}$ \\
\hline & & $2831^{*}$ & Male & 430 & $\mathrm{UC}$ & $\mathrm{CP}, \mathrm{RF}$ & Jun, Jul, Aug, Sep & I \\
\hline & & $2832^{*}$ & Male & 506 & $\mathrm{LC}$ & $\mathrm{RF}$ & Jun, Jul, Aug, Sep & $\mathrm{T}$ \\
\hline & & 2834 & Male & 494 & LC & $\mathrm{RF}, \mathrm{BP}$ & Jul, Aug & I \\
\hline & & $2835^{*}$ & Female & 603 & UC & $\mathrm{CP}, \mathrm{RF}$ & Jun, Jul, Aug, Sep & I \\
\hline & & 2837 & Female & 502 & LC & $\mathrm{RF}$ & Jun, Jul & $\mathrm{F}$ \\
\hline & & 2840 & Male & 442 & UC & $\mathrm{CP}, \mathrm{RF}$ & Jun, Jul & I \\
\hline & & 2842 & Male & 461 & $\mathrm{LC}$ & $\mathrm{RF}, \mathrm{BP}$ & Jul, Aug, Sep & I \\
\hline & \multirow[t]{7}{*}{ July } & 2822 & Female & 504 & $\mathrm{CC}$ & BG & Jul, Aug, Sep & F \\
\hline & & $2823^{*}$ & Female & 682 & $\mathrm{CC}$ & $\mathrm{BG}, \mathrm{CP}$ & Jul, Aug, Sep & I \\
\hline & & 2824 & Unknown & 495 & $\mathrm{LC}$ & $\mathrm{RF}, \mathrm{BP}$ & Jul, Aug & I \\
\hline & & 2825 & Female & 520 & $\mathrm{LC}$ & $\mathrm{RF}$, BP & Jul, Aug, Sep & I \\
\hline & & 2826 & Female & 537 & $\mathrm{LC}$ & $\mathrm{RF}$ & Jul & $\mathrm{F}$ \\
\hline & & 2833 & Female & 605 & $\mathrm{CC}$ & BG & Jul & $\mathrm{F}$ \\
\hline & & 2839 & Female & 504 & $\mathrm{LC}$ & $\mathrm{RF}$ & Jul & $\mathrm{F}$ \\
\hline \multirow[t]{15}{*}{2008} & \multirow[t]{3}{*}{ May } & 9647 & Female & 574 & $\mathrm{UC}$ & $\mathrm{CP}, \mathrm{RF}$ & May, Jun, Jul, Aug, Sep & I \\
\hline & & 9652 & Female & 560 & $\mathrm{UC}$ & $\mathrm{CP}, \mathrm{RF}$ & May, Jun, Jul, Aug, Sep & $\mathrm{T}$ \\
\hline & & 9667 & Female & 701 & $\mathrm{LC}$ & $\mathrm{RF}, \mathrm{BP}$ & Jun, Jul, Sep & I \\
\hline & \multirow[t]{7}{*}{ June } & 9640 & Male & 572 & $\mathrm{LC}$ & $\mathrm{RF}$ & Jun, Jul & $\mathrm{F}$ \\
\hline & & 9641 & Male & 606 & $\mathrm{CC}$ & BG & Jun, Jul, Aug & F \\
\hline & & 9642 & Female & 547 & $\mathrm{CC}$ & $\mathrm{BG}, \mathrm{CP}$ & Jun, Jul, Aug & I \\
\hline & & 9645 & Male & 515 & UC & RF & Jun, Jul & $\mathrm{F}$ \\
\hline & & 9650 & Male & 586 & $\mathrm{LC}$ & $\mathrm{RF}, \mathrm{BP}$ & Jun, Jul & I \\
\hline & & 9661 & Female & 836 & $\mathrm{CC}$ & BG & Jun, Jul, Aug & $\mathrm{F}$ \\
\hline & & 9666 & Male & 620 & $\mathrm{CC}$ & $\mathrm{BG}, \mathrm{CP}$ & Jun, Jul, Sep & I \\
\hline & \multirow[t]{5}{*}{ July } & 9639 & Male & 510 & $\mathrm{LC}$ & $\mathrm{RF}$ & Jul & $\mathrm{F}$ \\
\hline & & 9654 & Male & 554 & $\mathrm{UC}$ & RF & Jul, Aug, Sep & $\mathrm{F}$ \\
\hline & & 9655 & Male & 553 & LC & $\mathrm{RF}$ & Jul, Aug & $\mathrm{F}$ \\
\hline & & 9660 & Female & 519 & $\mathrm{UC}$ & $\mathrm{CP}, \mathrm{RF}$ & Jul, Aug & $\mathrm{T}$ \\
\hline & & 9663 & Female & 766 & $\mathrm{CC}$ & BG & Jul, Aug, Sep & $\mathrm{F}$ \\
\hline
\end{tabular}

have been detected by a receiver across the pass under slack tide conditions. The receiver was located on the southeastern side of the pass, $345 \mathrm{~m}$ from the shoreline on the northern side of the pass, within the range of the receiver under calm conditions, and these conditions were present during the time periods these fish were detected. The other 2 snook were each detected by only a single receiver away from the island of tagging, both by receivers on the western side of the pass. These receivers were located such that detection of a snook on the other side of the pass was extremely unlikely. Thus, the latter 2 instances of inter-island movements were valid but brief-both fish were detected on the island of tagging after the inter-island movement.

\section{DISCUSSION}

The present study adds to the growing literature on spawning ground fidelity for broadcast spawning fishes (e.g. Atlantic cod Gadus morhua, Jonsson 1996, Robichaud \& Rose 2001; Atlantic herring Clupea harengus, McQuinn 1997; weakfish Cynoscion nebulosus, Thorrold et al. 2001; plaice Pleuronectes platessa, Hunter et al. 2003). For the tag-recapture portion of the study, all snook recaptured during the spawning season were recaptured on the same island where they were tagged, regardless of recapture method, demonstrating fidelity to spawning grounds at the scale of the barrier island. This held true whether snook were recaptured within the same spawning season as they 
were tagged, or in the subsequent spawning season. Moreover, the low average distance, relative to island length, between tagging and recapture locations suggests that snook may show fidelity at an even smaller scale. For the acoustic telemetry portion of the study, most snook (88\%) were detected only on the same island they were tagged, and most of these fish were detected only in a single pass, also indicating islandlevel fidelity and the possibility of fidelity at an even smaller scale. These findings suggest spawning segregation by the snook population in Florida.

The recapture strategy used in the present study ensured that movements by snook during spawning would be detected. Seine sampling occurred along $28 \mathrm{~km}$ of coastal beach habitat used by snook during the spawning season, and would have detected interisland movement. Despite capturing $>2000$ snook and tagging $>1800$, no snook were recaptured on a different island from where they were tagged, suggesting that inter-island movement by adult snook of the size range sampled in the present study during spawning season is uncommon. Moreover, the use of external tags, anglers, and charter captains allowed us to use the effort of the very active recreational fishery that covers the entire estuary and coast to sample the snook population. Finally, the FWRI FIM program scanned 306 snook during the present study from June through October (87 in 2007, 219 in 2008), and recorded only one recapture in October 2008, within the estuary (D. Blewett pers. comm.). Since this single recapture was in a location and habitat that were not suitable for spawning, it was not included in the analysis.

Acoustic receiver placement was designed to give the highest probability of detecting tagged snook as they moved through the passes or used the passes for extended periods, and to specifically address the question: do snook show fidelity to a specific barrier island during spawning season? The receivers were placed in areas protected from the main tidal currents that flushed the passes because the sounds associated with the current would interfere with transmitter detection. They were placed close enough to the passes, however, to detect snook moving through and in proximity to slower current areas where snook are known to sometimes reside. Combined with the range of the receivers reaching the shoreline, the likelihood of snook being detected was high. Therefore, if snook had moved from one island or pass to another, they would very likely have been detected.

Although the present study sampled the size classes that dominate the snook population along the Gulf of Mexico coast, more data are needed to determine whether large (mostly female) snook also show this level of site fidelity. Snook are protandrous hermaphrodites, with a population-level sex ratio skewed toward males (male:female $=1.6: 1.0$ ) (Taylor et al. 2000). Moreover, females $<500 \mathrm{~mm}$ in fork length (equivalent to $452 \mathrm{~mm} \mathrm{SL;} \mathrm{Taylor} \mathrm{et} \mathrm{al.} \mathrm{2000)} \mathrm{are} \mathrm{rare,}$ and the predicted length at which the sex ratio is 1.0:1.0 is $553 \mathrm{~mm}$ SL on the Gulf of Mexico coast (Taylor et al. 2000). In the present study, the mean SL of tagged snook was $426 \mathrm{~mm}$, notably less than the size at which sex change appears to first occur (452 mm), and considerably less than the size $(553 \mathrm{~mm})$ at which the expected sex ratio is $1: 1$. It is therefore possible that males and small females that comprised the majority of the sampled population show strong spawning site fidelity, while larger females move among spawning locations, thereby providing genetic mixing within the population. However, the snook fitted with acoustic transmitters were among the largest snook captured, and also showed strong fidelity to spawning locations. Therefore, the results of the present study are likely to be valid for the snook population present on spawning grounds.

Fidelity to spawning grounds may make snook more susceptible to natural or anthropogenic disturbances. Coastal beaches, for example, are subject to beach nourishment programs to combat natural erosion processes. Effects of beach nourishment include an increase in suspended sediment throughout the water column, decreasing water clarity, and the loss of invertebrate assemblages, which are integral sources of sustenance for fish and many other organisms (Peterson \& Bishop 2005). Loss of prey for larger predators may force fish to migrate in search of more suitable habitat with a larger prey selection, but if they show fidelity to specific spawning grounds, movement from areas impacted by beach renourishment may inhibit spawning. Dredging and shoreline hardening may produce similar impacts on snook and other species that use beach habitats. In addition, although catch and release fishing of spawning aggregations does not have shortterm deleterious impacts (Lowerre-Barbieri et al. 2003), the effect of multiple catch and release events on snook that show site fidelity should be examined.

Natural disturbances tend to be patchy in the spatial extent of their effects, and this patchiness may result in localized impacts on spawning locations. Damage from hurricanes, for example, can cause fish displacement (Letourneur 1996, Paerl et al. 2001). Waves and currents from hurricanes can move large amounts of sediment, changing beach and barrier island topography such that inlets may be filled or new inlets opened. This may in turn cause hydrographic changes that affect larval transport from spawning locations, and thus affect spawning success. Without information on abundance and fidelity of snook at spawning sites, predictions about such impacts are not possible, and this may hinder effective fisheries management. 
Harmful algal blooms (HABs) are becoming a disturbance of increasing concern in many coastal areas throughout the world (e.g. Anderson et al. 2002). The alga most likely to impact spawning snook along the Gulf Florida is Karenia brevis (red tide). Red tide blooms cause an increase in brevetoxins in the water, which negatively affects a range of organisms including fish (Millie et al. 1997), often causing large fish kills. Red tide blooms are spatially patchy and their coverage and duration unpredictable. Although little is known about the effects of red tide on snook, it is relatively rare that snook die in large numbers during a red tide bloom. Rather, anecdotal evidence suggests snook are displaced by red tide, and move to unaffected areas, typically those with salinities too low to sustain $K$. brevis. If this displacement inhibits spawning, because salinity requirements for snook egg and sperm viability are similar to that for $K$. brevis, then even if red tide does not cause large kills of snook it may reduce spawning success and subsequent year-class strength for the area affected by red tide. If this is the case, data on abundance and fidelity of snook at spawning sites, and linkages between these spawning sites and larval recruitment and juvenile habitats, would be useful for predicting population-level effects of red tide on year-class strength in years following red tide events.

Common snook in Florida are managed as 2 stocks (Atlantic and Gulf of Mexico) based upon genetic data (Tringali \& Bert 1996). The present study suggests that there may be further division of these stocks by segregation of spawning groups. Although some degree of spawning segregation is implicit under typical fisheries management, such an approach might not be suitable if spawning segregation occurred to a sufficient degree. For example, in an extreme situation, managing as a single stock when in fact there exists significant sub-stock structure may result in local extinctions, substructure overfishing, and reductions in productivity (Frank \& Brickman 2000). Whereas these are not realistic scenarios for common snook, in part because the fishery is a highly regulated recreational fishery, the effects of anthropogenic and natural disturbances and stressors may occur in such a manner as to require that such spawning segregation is accounted for in management strategies. In Florida, the sample size used to determine the Atlantic versus Gulf of Mexico stock structure (Tringali \& Bert 1996) may have been too low ( $\mathrm{N}=138$ on the Gulf of Mexico coast) to determine effects of spawning segregation, and may need to be revisited.

Two scenarios may reduce the population level effect of spawning segregation suggested by the present study. First, snook smaller than those sampled in the present study (i.e. immature) may undergo larger scale movements before developing site fidelity once they reach maturity. In this scenario, snook that were spawned and resided as juveniles in one estuarine system may move to distant locations, thereby reducing population segregation. Such movements were observed for 2 snook that were tagged as juveniles in Charlotte Harbor mangrove creeks and recaptured in Sarasota Bay (>55 km) and Gasparilla Sound (>42 km) (A. J. Adams unpubl. data). Alternatively, once reaching a threshold size, large females may use multiple spawning sites along a coastline as a bet-hedging strategy for successful reproduction, therefore it is only the smaller males and females that exhibit site fidelity.

As fisheries management begins to examine the use of stock enhancement as a management strategy for coastal fishes, potential spawning segregation influence on genetic and ontogenetic effects should be taken into consideration. A responsible approach to stock enhancement requires that negative impacts on local gene pools are avoided and that local genetic structure is maintained (e.g. Tringali \& Leber 1999). In addition, ontogenetic connectivity between spawning locations, larval transport, and juvenile and subadult habitats may require a better understanding of spatiotemporal characteristics of local populations of snook and other broadcast spawning marine fishes. For example, are hydrodynamics of the Gulf of Mexico coast and adjacent estuaries such that one spawning location is more likely to provide larvae to a particular wetland that harbors snook nursery habitat? If spawning site fidelity results from philopatry, are specific spawning locations and nursery habitats linked?

Future research should examine snook spawning ground fidelity over a greater temporal and spatial scale. Confirmation of snook fidelity over 2 or more years (rather than 1 yr between tag and recapture, as in the present study) would support the conclusion of the preponderance of spawning ground fidelity in the snook population. Furthermore, the barrier island geography of southwest Florida, with multiple inlets separating relatively small islands, may promote fidelity, whereas snook spawning along longer continuous shorelines (e.g. the Atlantic coast of Florida) may exhibit greater range of movement over a spawning season.

Future research should examine the mechanism for the observed fidelity to spawning grounds, because each mechanism (spawning group, philopatry, learned) has different implications for how the population will respond to disturbances. The mechanism that would likely result in a population being least affected by spatially patchy disturbances, such as red tide, is spawning group fidelity. This is because fish develop site fidelity at first maturity and are likely searching for other mature individuals prior to the first spawning 
event. In this case, newly mature individuals may congregate at a location that provides suitable spawning conditions, whether or not other fish have spawned there before, and regardless of internal programming that might lead to philopatric site selection. This allows for colonization of new spawning locations without prior experience. In contrast, if snook find spawning locations via social learning, the loss of a sufficient number of individuals with the required social memory will mean that future generations cannot be guided to appropriate spawning locations. If philopatry is the mechanism by which snook find spawning locations, loss of multiple year classes of the site's lineage would result in loss of spawning individuals at that site.

In conclusion, the findings of the present study indicate an additional dimension to common snook life history that should be taken into consideration in future research and management. Future research might examine the extent to which this level of spawning ground fidelity occurs in other regions with different habitat characteristics. The southeast coast of Florida, for example, has primarily artificially maintained inlets between estuaries and the Atlantic Ocean, and so may spur different behavior by spawning-stage snook. Similarly, common snook closer to the center of their geographic distribution (Central America) are often found in areas where rivers empty directly into the ocean, rather than the extensive estuaries of southwest Florida, which may present different challenges to snook spawning. Examining possible linkages between spawning grounds and larval recruitment locations and juvenile habitats should be a next step in research. Such information would be useful for prioritizing habitat conservation. Finally, understanding that adult snook show site fidelity to spawning grounds should be incorporated into management strategies so that proactive measures can be taken if an important spawning ground is affected by a disturbance, whether natural or anthropogenic.

Acknowledgements. This research was funded by a grant from the Florida Fish and Wildlife Conservation Commission (grant no. 06125 to R. Pierce), Mote Scientific Foundation (to A.J.A.), and an NSF REU grant to J. Gelsleichter. We thank A. Barbour, T. Barker, R. Boucek, M. Hammond, M. McGraw, C. Murray, S. Yess, T. Yess, and J. Zehnder for field assistance, and D. R. Gulnac and D. K. Gulnac for facilities. Tagging was conducted according to standards set by the Mote Marine Laboratory Institutional Animal Care and Use Committee (IACUC permit no. 0704aa1). Fig. 1 was prepared by J. Ott.

\section{LITERATURE CITED}

Adams AJ, Wolfe RK, Pine WE, Thornton BI (2006) Efficacy of PIT tags and an autonomous antenna system to study the juvenile life stage of an estuarine-dependent fish. Estuar Coasts 29:311-317
Aguilar-Perera A, Aguilar-Davila W (1996) A spawning aggregation of Nassau grouper Epinephelus striatus (Pisces: Serranidae) in the Mexican Caribbean. Environ Biol Fishes 45:351-361

Anderson DM, Glibert PM, Burkholder JM (2002) Harmful algal blooms and eutrophication: nutrient sources, composition, and consequences. Estuaries 25:704-726

Beets J, Friedlander A (1999) Evaluation of a conservation strategy: a spawning aggregation closure for red hind, Epinephelus guttatus, in the U.S. Virgin Islands. Environ Biol Fishes 55:91-98

Colin PL (1996) Longevity of some coral reef fish spawning aggregations. Copeia 1996:189-192

> Frank KT, Brickman D (2000) Allee effects and compensatory population dynamics within a stock complex. Can J Fish Aquat Sci 57:513-517

Groot C, Margolis L (1991) Pacific salmon life histories. University of British Columbia Press, Vancouver, BC

Hammett KM (1990) Land use, water use, streamflow characteristics, and water quality characteristics of the Charlotte Harbor inflow area, Florida. US Geol Surv Water Supply Pap 2359-A, USGS, St. Petersburg, FL

Hanski I, Gilpin ME (1997) Metapopulation biology: ecology, genetics and evolution. Academic Press, Edinburgh

Hunter E, Metcalf JD, Reynolds JD (2003) Migration route and spawning area fidelity by North Sea plaice. Proc R Soc Lond B Biol Sci 270:2097-2103

Jonsson J (1996) Tagging of cod (Gadus morhua) in Icelandic waters 1948-1986. Rit Fiskid 14:7-82

Letourneur Y (1996) Dynamics of fish communities on Reunion fringing reefs, Indian Ocean. II. Patterns of temporal fluctuations. J Exp Mar Biol Ecol 195:31-52

Lowerre-Barbieri SK, Vose FE, Whittington JA (2003) Catchand-release fishing on a spawning aggregation of common snook: Does it affect reproductive output? Trans Am Fish Soc 132:940-952

> McQuinn IH (1997) Metapopulations and the Atlantic herring. Rev Fish Biol Fish 7:297-329

Millie DF, Schofield OM, Kirkpatrick GJ, Johnsen G, Tester PA, Vinyard BT (1997) Detection of harmful algal blooms using photopigments and absorption signatures: a case study of the Florida red tide dinoflagellate, Gymnodinium breve. Limnol Oceanogr 42:1240-1251

Paerl HW, Bales JD, Ausley LW, Buzzelli CP and others (2001) Ecosystem impacts of three sequential hurricanes (Dennis, Floyd, and Irene) on the United States' largest lagoonal estuary, Pamlico Sound, NC. Proc Natl Acad Sci USA 98: 5655-5660

> Peterson CH, Bishop MJ (2005) Assessing the environmental impacts of beach nourishment. Bioscience 55: 887-896

Poulakis GR, Blewett DA, Mitchell ME (2003) The effects of season and proximity to fringing mangroves on seagrassassociated fish communities in Charlotte Harbor, Florida. Gulf Mex Sci 21:171-184

> Robichaud D, Rose GA (2001) Multiyear homing of Atlantic cod to a spawning ground. Can J Fish Aquat Sci 58: $2325-2329$

> Smedbol RK, Stephenson RL (2001) The importance of managing within-species diversity in cod and herring fisheries of the north-western Atlantic. J Fish Biol 59:109-128

> Taylor RG, Grier HJ, Whittington JA (1998) Spawning rhythms of common snook in Florida. J Fish Biol 53: 502-520

Taylor RG, Whittington JA, Grier HJ, Crabtree RE (2000) Age, growth, maturation, and protandric sex reversal in common snook, Centropomus undecimalis, from the east and 
west coasts of South Florida. Fish Bull 98:612-624

Thorrold SR, Latkoczy C, Swart PK, Jones CM (2001) Natal homing in a marine fish metapopulation. Science 291: 297-299

Tringali MD, Bert TM (1996) The genetic stock structure of common snook (Centropomus undecimalis). Can J Fish Aquat Sci 53:974-984

Tringali MD, Leber KM (1999) Genetic considerations during

Editorial responsibility: Jana Davis,

Annapolis, Maryland, USA the experimental and expanded phases of snook stock enhancement. Bull Natl Res Inst Aquacult (Suppl 1): 109-119

> Vargo GA (2009) A brief summary of the physiology and ecology of Karenia brevis Davis (G. Hansen and Moestrup comb. nov.) red tides on the West Florida Shelf and of hypotheses posed for their initiation, growth, maintenance, and termination. Harmful Algae 8:573-584

Submitted: March 16, 2009; Accepted: July 6, 2009

Proofs received from author(s): August 22, 2009 